\title{
Creation of fine silk fabric of mulberry silkworms through inbreed system mixing methods
}

\author{
Umirzak Daniyarov ${ }^{1, *}$, Gulbakhor Abdrimova ${ }^{2}$, Narzulla Rajabov ${ }^{1}$, Khurniso \\ Rakhmanova ${ }^{1}$, and Nargiza Turgunboeva ${ }^{1}$ \\ ${ }^{1}$ Tashkent State Agrarian University, University str., 2, Tashkent province, 100140 Uzbekistan \\ ${ }^{2}$ Nukus Branch of Tashkent State Agrarian University, Nukus, Republic of Karakalpakstan, \\ Uzbekistan
}

\begin{abstract}
Worldwide, special attention is paid to the creation of high-tech silkworm breeds and hybrids of mulberry silkworms. Inbreed-breed hybrids with high technological performance of mulberry silkworm cocoon fiber have been created. Inbreed systems and new hybrids with fine silk fiber Kitayskaya 108, Ya-120, Ipakchi 1 x Ipakchi 2, Ipakchi 2 x Ipakchi 1 regionalized hybrids dry cocoon weight $(0.715-0.841 \mathrm{~g}$; control - 0.715$0.734 \mathrm{~g})$, continuous cocoon fiber length $(731-888 \mathrm{~m}$; control - 744-776 $\mathrm{m})$, cocoon fiber metric number $(3020-3319 \mathrm{~m} / \mathrm{g}$; control - 3090-3103 m/g) proved to be significantly superior.
\end{abstract}

\section{Introduction}

Today, more than 22 countries around the world produce live cocoons and produce an average of 177,832 thousand tons of silk fiber a year. $82.1 \%$ of the silk produced is from the People's Republic of China, $16.1 \%$ from India, $0.6 \%$ from Uzbekistan, $0.4 \%$ from Thailand, $0.3 \%$ from Brazil, $0.2 \%$ from Vietnam and the remaining $0.3 \%$ from other silk growers. States [1-4]. Developed countries such as Japan, the People's Republic of China, India, South Korea and Uzbekistan are leading in the creation of fine-fiber breeds and hybrids, which are very important for industrial production $[5,7]$.

Worldwide, special attention is paid to the creation of high-tech silkworm breeds and hybrids of mulberry silkworms. High efficiency is achieved through the selection of silk fibers by technological characteristics, the determination of the correlation between the characteristics of silk fiber and reproductive, cocoon productivity, and their use in selection processes $[2,5]$. The creation of high-quality and industrial hybrids of fiber that meet the requirements of the world silk market and the silk industry, as well as the improvement of genetics and selection processes of mulberry silkworms is of great scientific and practical importance $[1,3,4]$.

Inbreeding in mulberry silkworms has been studied by local and international scientists. They found that it was advisable to select the best few (3-4) families based on the average

\footnotetext{
${ }^{*}$ Corresponding author: umirzak77@,mail.ru
} 
performance of the character being selected for the silkworm. In well-separated families, which are the heads of the "systems", the most complete offspring are selected and included in the crossbreeding - siblings: within the systems, the offspring resulting from such crossbreeds are compared, the best family is selected, and so on. Because inbreeding is associated with the automatic homozygous transition of genetic factors, at the 6-7 inbrid generation level, each selected system generation has a practically constant (invariability) of the selected trait in mass industrial reproduction [1-5, 8-10].

Reproduction by inbreeding allows the genotype of the families under analysis to be maintained until their characteristics are obtained [6]. The best inbreed systems are then preserved, but as a rule, especially in the early stages, all selected families are intertwined with each other to synthesize the best genotypes on a combination value.

Proving that positive compensatory complexes of genes accumulate under the influence of depressive motives, the above-mentioned author was able to develop three methods based on selection on survival in a depressed system with genes that showed pleiotropic phenotypic effect in both recessive and dominant hemispheric, surviving individuals in mulberry silkworms.

1. Selection for the combinatorial ability of inbreed systems against the background of the action of unidentified mutations.

2. Selection against the background of the depressant action of amyotrophic and meiotic parthenogenesis.

3. Selection against the background of inbriding.

One of the causes of heterosis of mulberry silkworm hybrids in a series of studies is the coordinated action of optimal genes that control survival. They are scattered across individual individuals of the population. Their integration into the genotype of the parents of hybrids is accomplished by selecting viability in homozygous systems for some semimetallic mutation that reduces survival by $20-30 \%$. Such selection of mutant system families increases survival to normal as a result of the formation of a powerful compensatory complex of genes.

During inbreeding, not only is the population randomly divided into inbreed systems that remain different in terms of combinatorial ability, but also the active formation of combinatorial ability is realized. This is due to the fact that a sufficient number of semimetals in the population move from a state of heterosis to a homozygous state during inbreeding and depress the system. Not all of the hemispheres are homozygous at the same time, but gradually, over a series of inbreed generations. In this case, the transition of semimetals to the homozygous state and depression serve as a triggering mechanism for the gradual formation of the compensatory complex in inbreed systems, resulting in the formation of combinatorial ability. This can only be achieved successfully if the nature of the hemispheres and the reserve of genotypes contribute to the emergence of the compensatory complex, which is a guarantee of heterosis in F1 hybrids. To select the best among hundreds of thousands of inbreed systems, a special genetic analysis based on the study of the quality of intersystem hybrids is required [4, 7]].

According to the theory of some scientists, in order to create highly heterozygous inbreed systems, it is necessary to conduct a strict selection of inbreed systems for viability $[6,7]$. The effectiveness of such selection can be tested by studying heterosis in different kinship and alien crosses. The most useful and the most reliable in terms of proof is to confuse inbreed systems with their primary breeds: topcrosses (breed $\mathrm{x}$ inbreed system), bottomcrosses (breed $\mathrm{x}$ inbreed), incrosses (breed-inbreed system $1 \mathrm{x}$ inbreed system 2 ). In the process of selective survival of inbreed systems, there is a complete disappearance of inbreed depression in the late generations of inbreed, the increase in the yield of inbreed systems coincides with the increase in the yield of top and bottomprosses obtained from them, the formation of combinatorial ability compatible with post-generation testing. 


\section{Materials and methods}

In our experiments, for five years (2016-2020) hybrids were created between the systems of fine silk fiber Yaponskaya 66, Kitayskaya 108 and Liniya 48, Liniya 51 inbreeding all (from J4 to J9). Inbreed systems and breeds were fed as a family, according to the generally accepted technology of feeding mulberry silkworms from 15-20 families. All collected silkworm seeds, worms, cocoons were statistically processed to digital indicators. Indicators of hybrids were also recorded and analyzed. They were carried out according to the following scheme (Fig. 1):

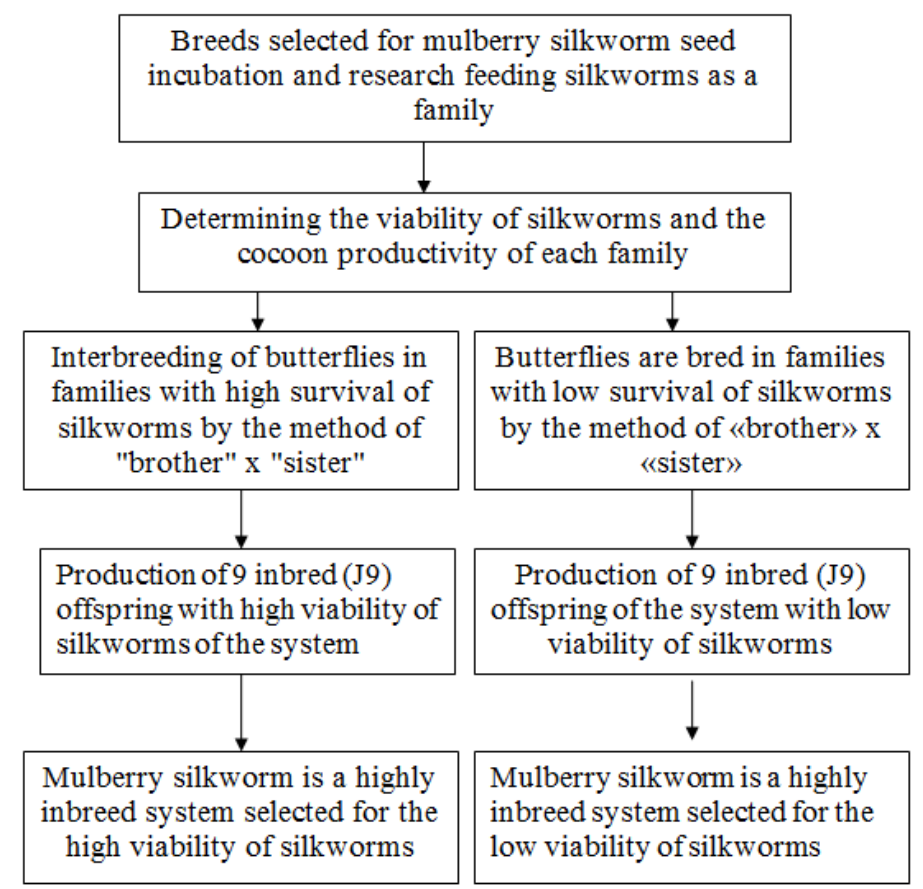

Fig. 1. Scheme for the creation of high-inbreed systems selected for the high or low viability of mulberry silkworms.

\section{Results and discussion}

In order to evaluate new systems as a hybrid-component, in 2019 and 2020 new hybrids of fine silk fiber were hybridized with inbreed systems [10] The results are presented in Table 1.

To better demonstrate the effect of heterosis, mixing was carried out between systems derived from different breeds.

Ipakchi-1 x Ipakchi-2, Ipakchi-2 x Ipakchi-1 regionalized hybrids serve as control. 
Table 1. Biological indicators of new hybrids (2019-2020).

\begin{tabular}{|c|c|c|c|c|c|}
\hline$\#$ & New hybrids & $\begin{array}{c}\text { Survival of } \\
\text { silkworms, } \\
\mathbf{\%}\end{array}$ & $\begin{array}{c}\text { Shell } \\
\text { weight, } \\
\text { mg }\end{array}$ & $\begin{array}{c}\text { Cocoon } \\
\text { weight, g }\end{array}$ & Silk, \% \\
\hline 1 & F-1 x (L-48 x K-108) & $92.4 * \pm 1.8$ & $1.94 \pm 0.03$ & $411 \pm 7.2$ & $21.2 * \pm 0.3$ \\
\hline 2 & (L-48 x K-108) x F-1 & $90.7 \pm 1.1$ & $1.89 \pm 0.03$ & $403 \pm 6.0$ & $21.4 \pm 0.2$ \\
\hline 3 & F-2 x (L-48 x K-108) & $87.3 \pm 1.0$ & $1.88 \pm 0.03$ & $400 \pm 6.1$ & $21.3 \pm 0.2$ \\
\hline 4 & (L-48 x K-108) x F-2 & $92.7 \pm 2.0$ & $1.83 \pm 0.03$ & $392 \pm 2.5$ & $21.5 \pm 0.3$ \\
\hline 5 & F-3 x (L-51 x YaP-66) & $77.1 \pm 1.9$ & $1.90 \pm 0.02$ & $414 \pm 7.6$ & $21.8 \pm 0.3$ \\
\hline 6 & (L-51 x YaP-66) x F-3 & $91.9 \pm 2.1$ & $1.97 \pm 0.02$ & $438 \pm 8.3$ & $22.2 \pm 0.3$ \\
\hline 7 & F-3 x (L-51 x K-108) (Navruz-3) & $86.6 \pm 1.9$ & $1.81 \pm 0.03$ & $389 \pm 3.5$ & $21.5 \pm 0.2$ \\
\hline 8 & (L-51 x K-108) x F-3 & $94.9 \pm 2.1$ & $1.80 \pm 0.02$ & $369 \pm 3.6$ & $20.5 \pm 0.2$ \\
\hline 9 & F-4 x (L-51 x K-108) & $81.5 \pm 1.2$ & $1.98 \pm 0.02$ & $434 \pm 8.0$ & $20.5 \pm 0.2$ \\
\hline 10 & (L-51 x K-108) x F-4 & $86.9 \pm 1.3$ & $1.83 \pm 0.03$ & $391 \pm 3.7$ & $22.0 \pm 0.3$ \\
\hline 11 & F-4 x (L-51 x YaP-66) & $85.9 \pm 1.1$ & $1.77 \pm 0.03$ & $366 \pm 2.9$ & $20.7 \pm 0.2$ \\
\hline 12 & (L-51 x YaP-66) x F-4 (Navruz-4) & $91.2 \pm 2.0$ & $1.88 \pm 0.03$ & $398 \pm 3.0$ & $21.2 \pm 0.2$ \\
\hline 13 & $\begin{array}{c}\text { Ipakchi 1 x Ipakchi 2 } \\
\text { (comparative) }\end{array}$ & $92.7 \pm 0.9$ & $1.74 \pm 0.02$ & $410 \pm 6.3$ & $23.6 \pm 0.4$ \\
\hline 14 & $\begin{array}{c}\text { Ipakchi 2 x Ipakchi 1 } \\
\text { (comparative) }\end{array}$ & $93.3 \pm 0.9$ & $1.88 \pm 0.02$ & $438 \pm 6.7$ & $23.3 \pm 0.4$ \\
\hline
\end{tabular}

$* P d=0.999$

As can be seen from Table 1, the hybrids between inbreed systems and backcrosses lag behind the Ipakchi-1 x Ipakchi-2, Ipakchi-2 x Ipakchi-1 zoning hybrids in terms of cocoon weight.

The shell weight of new hybrids can be compared to the shell weight of regionalized hybrids. The viability of silkworms is significantly lower than that of Ipakchi-1 x Ipakchi-2, Ipakchi-2 x Ipakchi-1. Inbreed systems are composed of large cocoons Liniya 48 and Liniya 51, which are not distinguished from others by the good viability of silkworms, so mixing with them has slightly reduced the viability of hybrids. Stabilizing the viability of inbreed systems leads to an improvement in the performance of the hybrids in which they participate.

In our study, the technological properties of silk fibers of new hybrids for an average of 2 years are of particular importance (Table 2).

Table 2. Results of testing of technological properties of new hybrid cocoon fibers (2019-2020).

\begin{tabular}{|c|c|c|c|c|c|c|c|c|}
\hline \multirow[b]{2}{*}{$\#$} & \multirow[b]{2}{*}{ Hybrids } & \multirow{2}{*}{ 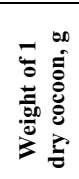 } & \multicolumn{2}{|c|}{ Yield, \% } & \multirow{2}{*}{ 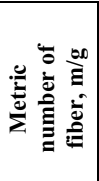 } & \multirow{2}{*}{ 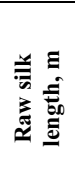 } & \multirow{2}{*}{ 包 } & \multirow{2}{*}{ 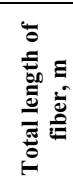 } \\
\hline & & & $\begin{array}{l}\text { Raw } \\
\text { silk }\end{array}$ & $\begin{array}{c}\text { Silk } \\
\text { products }\end{array}$ & & & & \\
\hline 1 & F-1x(L-48x Kit.108) & 0.786 & 42.72 & 47.68 & 3,215 & 919 & 89.57 & 1,139 \\
\hline 3 & F-2x(L-48xKit.108) & 0.739 & 44.06 & 49.17 & 3,298 & 817 & 89.61 & 1,000 \\
\hline 4 & (L-48xKit.108)xF-2 & 0.774 & 41.51 & 48.17 & 3,295 & 871 & 86.17 & 1,106 \\
\hline 5 & $\mathrm{~F}-3 \mathrm{x}(\mathrm{L}-51 \times \mathrm{YaP} .66)$ & 0.755 & 43.50 & 48.84 & 3,256 & 874 & 89.04 & 1,131 \\
\hline 6 & $(\mathrm{~L}-51 \times Y a P .66) \times \mathrm{F}-3$ & 0.854 & 43.57 & 49.27 & 3,092 & 840 & 82.43 & 1,189 \\
\hline 7 & $\begin{array}{c}\text { F-3x(L-51 x Kit.108) } \\
(\text { Navruz-3) }\end{array}$ & 0.741 & 41.08 & 46.85 & 3,303 & 953 & 87.70 & 1,153 \\
\hline 8 & (L-51xKit.108) x F-3 & 0.753 & 42.62 & 48.55 & 3,020 & 770 & 87.78 & 1,030 \\
\hline 9 & F-4x(L-51 x Kit.108) & 0.811 & 39.09 & 46.17 & 3,103 & 766 & 84.06 & 1,197 \\
\hline 10 & (L-51xKit.108) x F-4 & 0.759 & 42.05 & 47.31 & 3,235 & 809 & 83.81 & 1,026 \\
\hline 11 & F-4x(L-51 x YaP.66) & 0.760 & 41.88 & 47.89 & 3,280 & 855 & 87.44 & 1,144 \\
\hline 12 & $\begin{array}{c}\text { (L-51xYaP.66) x F-4 } \\
(\text { Navruz-4) }\end{array}$ & 0.739 & 43.34 & 49.33 & 3,399 & 956 & 87.86 & 1,015 \\
\hline 13 & Ipakchi 1 x Ipakchi 2 & 0.778 & 40.56 & 47.22 & 3,128 & 757 & 85.89 & 1,079 \\
\hline 14 & Ipakchi 2x Ipakchi 1 & 0.773 & 42.69 & 47.61 & 3,198 & 800 & 89.67 & 1,065 \\
\hline
\end{tabular}


As can be seen from Table 2, the test hybrids lag behind the zoned Ipakchi-1 x Ipakchi2, Ipakchi-2 x Ipakchi-1 in terms of dry cocoon weight and length of unbroken cocoon fiber. It follows that the hybridization of breeds with inbreed systems leads to an increase in the technological performance of mulberry silkworm cocoon fiber. The obtained new hybrids were tested and regionalized in production F-3x (L-51x Kit 108) (Navruz-3), (L$51 x Y a P$ 66) x F-4 (Navruz-4). Photos of the hybrids by development periods are given below (Fig. 2).

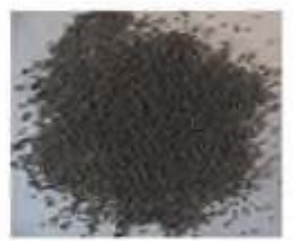

EGGS

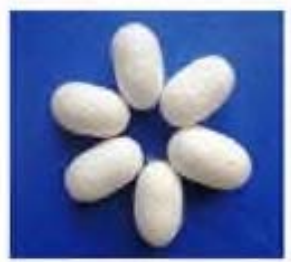

SII.K COCOON

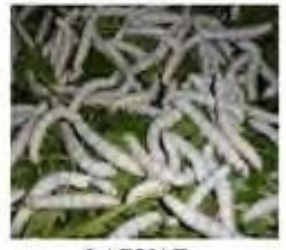

LARVAE

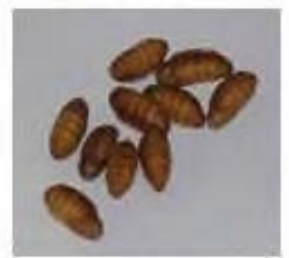

SILKWORM

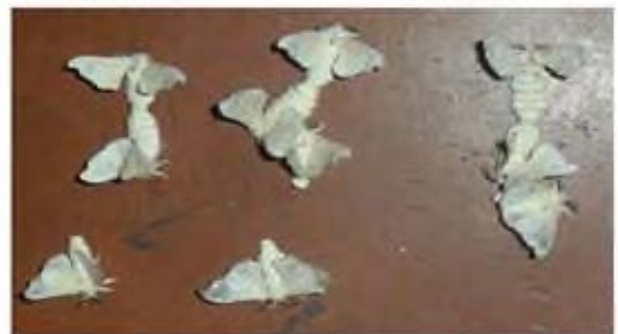

BUTTERFLIES

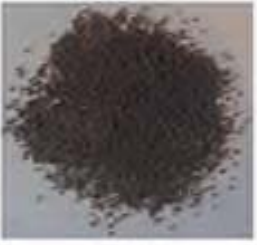

EGGS

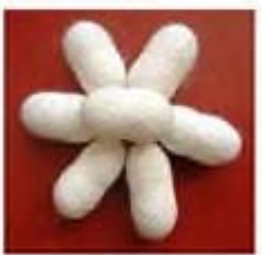

SILK COCOON

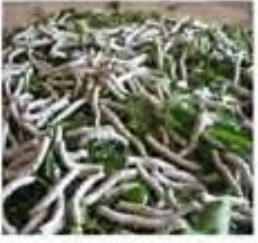

LARVAE

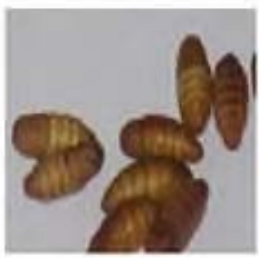

SII.KWORM

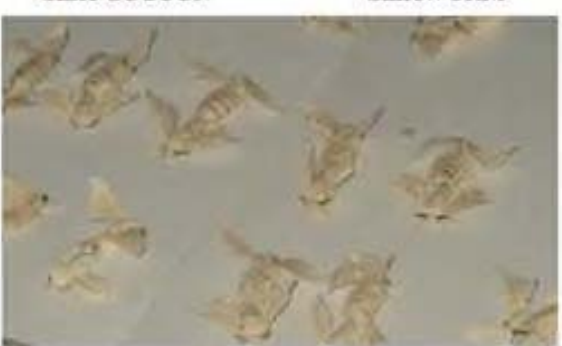

BUTTERFLIES

DEVELOPMENT STAGES OF THE HYBRID "NAVRUZ-4"

Fig. 2. Development stages of the hybrid silkworms.

\section{Conclusions}

Another way to improve the quality of cocoon fiber is the hybridization of inbreed systems with fine silk fibers, which against the background of high heterosis leads to improvements in the technological and other properties of mulberry silkworm cocoon fiber and followings aspects of this research should be highlighted:

- Large-scale Liniya 48 and Liniya 51 selection systems were used as material for the experiment.

- Three inbreed generations (J7, J8, J9) were studied and the reaction of the strains to inbreeds was determined in systems with targeted selection. 
- As a result of the research, it was determined that the tested hybrids have an advantage in terms of dry cocoon weight over the regionalized Ipakchi 1 x Ipakchi 2, Ipakchi 2 x Ipakchi 1 hybrids.

The study of three inbreed generations (J7, J8, J9) with a choice of plus and minus in terms of survival allowed to draw the following conclusions:

- Carrying out systemic reproduction for 9 generations with intensive survival selection leads to the complete elimination of inbreed depression in the late generations of inbreeding;

- Selection of inbreed systems, selected for viability, increases the viability of worms, metric number, total fiber length and cocoon fiber length without interruption;

- There is no difference in biological and technological parameters between the inbreed systems of silkworms selected for increased and reduced viability;

- Hybridization of fine silk fibers with inbreed systems leads to an improvement in the technological performance of mulberry silkworm cocoons.

- The new hybrids were tested and regionalized in the production of F-3x (L-51 $x$ Kit.108) (Navruz-3), (L-51xYap.66) x F-4 (Navruz-4).

\section{References}

1. E. Talebi, G. Subramanya, S. Bakkappa, Journal of Agricultural Biological Science, 5, 52-55 (2010)

2. J. Doreswami, S. Gopal, H. Hagedorn, Journal of insect science, 12(1), 21 (2012)

3. B. Bindroo, S. Manthira Moorthy, International Journal of Biodiversity, 9 (2014)

4. X. Ruiz, M. Almanza, Chilean journal of agricultural research, 78(4), 569-579 (2018)

5. L. Ovssenska, Silk, 1, 10-12 (1994)

6. M. Hussain, S. A. Khan, M. Naeem, International Journal of Agriculture and Biology, 13(1), 11 (2011)

7. V. Strunnikov, Nauka, 3-103 (1994)

8. M. Hussain, S. A. Khan, M. Naeem, M. Nasir, Pakistan Journal of Zoology, 43(5), 7 (2011)

9. M. Hussain, S. Khan, M. Aslam, African Journal of Food Science, 4(5), 300-302 (2010)

10. S. Navruzov, B. Nasirilaev, N. Rajabov, U. Khudayberdieva, Theoretical \& Applied Science, 144-148 (2020) 